\title{
USTAZ ABU BAKAR AL-BAQIR: ULAMA DAN PEJUANG KEMERDEKAAN TANAH MELAYU Ustaz Abu Bakar al-Baqir: Ulama and Freedom Fighter of Malaya
}

\author{
${ }^{1}$ KAMARUL AFENDEY BIN HAMIMI \\ ${ }^{2}$ AHMAD ZULLAILI BIN ZAMRI \\ Jabatan Pengajian Am, Universiti Kuala Lumpur-Royal College of Medicine Perak, \\ No. 3 Jalan Greentown, 31450, Ipoh, Perak \\ 'kamarulafendey@unikl.edu.my,2ahmadzullaili@unikl.edu.my \\ Diterima: 9 Februari 2018 / Dibaiki: 18 April 2018
}

\begin{abstract}
Abstrak Kertas kerja ini menganalisis peranan Ustaz Abu Bakar al-Baqir iaitu lama reformis tempatan yang konsisten menentang British sehingga terpenjara pada 1948. Beliau turut menubuhkan Maahad al-Ehya Assyariff untuk memodenkan sistem pendidikan pondok di samping meniupkan semangat kemerdekaan kepada pelajar dan masyarakat di sekelilingnya. Objektif kajian ini adalah untuk mengetengahkan sumbangan Ustaz Abu Bakar al-Baqir sebagai seorang ulama dan pejuang kemerdekaan menentang British sekitar 1934 sehingga 1957 di Perak. Kajian ini berbentuk historiografi yang menggunakan kaedah kualitatif dengan pendekatan analisis kandungan. Dua jenis sumber digunakan dalam kajian ini iaitu sumber primer dan sekunder. Sumber primer adalah seperti mendapatkan dokumen dan fail di Arkib Negara Malaysia, sumber pejabat kolonial British di samping menemu bual ahli keluarga dan murid Ustaz Abu Bakar al-Baqir. Sumber sekunder pula diperoleh melalui buku, surat khabar dan kertas kerja seminar yang berkaitan dengan perjuangan beliau. Hasil kajian mendapati para pelajarnya terdedah dengan semangat kemerdekaan ini ekoran guru-guru reformis dari Indonesia yang terdedah dengan perjuangan menentang Belanda mengajar di Maahad al-Ehya Assyariff. Selain itu, hubungan baik Ustaz Abu Bakar al-Baqir dengan Ibrahim Yaakub selaku penggerak Kesatuan Melayu Muda (KMM) dan Dr. Burhanuddin al-Helmy yang memimpin Parti Kebangsaan Melayu Muda (PKMM) menjadikan Maahad al-Ehya Assyariff sebagai markas politik menentang British sehingga tertubuhnya Parti Hizbul Muslimin di bawah pimpinan Ustaz Abu Bakar al-Baqir.
\end{abstract}


Kata kunci: Maahad al-Ehya Assyariff, Hizbul Muslimin, British, Kaum Muda, Parti Kebangsaan Melayu Malaya (PKMM), Kesatuan Melayu Muda (KMM).

Abstract This paper attempts to analyze the role played by Ustaz Abu Bakar al-Baqir, a local reformist religious leader who consistently opposed the British until he was imprisoned by them in 1948. He established the Maahad al-Ehya Assyariff with the aim of modernizing the religious education system besides stoking the spirit of freedom among his students and the society around him. The objective of this study is to highlight the contributions of Ustaz Abu Bakar al-Baqir as a religious leader as well as a freedom fighter who opposed British rule in Perak from around 1934 until 1957. This is a historiographical research which uses qualitative methodology with a content analysis approach. Two different sources of information are used for this study namely primary and secondary sources. Primary sources include documents and files from the Malaysian National Archives and official documents from the British Colonial office, besides interviewing family members as well as former students of Ustaz Abu Bakar al-Baqir. On the other hand, secondary sources include books, newspapers and seminar report relating to his struggle. The findings of the study show that his students were exposed to the struggle for Independence through the direct influence of the reformist teachers from Indonesia who were teaching at the Maahad al-Ehya Assyariff. These teachers had already been involved in the fight against the Dutch colonialists in Indonesia. In addition to this, the close relationship of Ustaz Abu Bakar al-Baqir with Ibrahim Yaakub, the prime mover of Kesatuan Melayu Muda (KMM) and Dr. Burhanuddin al-Helmy, the leader of Parti Kebangsaan Melayu Muda (PKMM), projected Maahad al-Ehya Assyariff as the political front that opposed British rule until the founding of the Parti Hizbul Muslimin under the leadership of Ustaz Abu Bakar al-Baqir.

Keywords: Maahad al-Ehya Assyariff, Hizbul Muslimin, British, Kaum Muda, Malay Nationalist Party (MNP), Young Malays Union. 


\section{PENDAHULUAN}

Ustaz Abu Bakar al-Baqir atau nama sebenarnya Abu Bakar bin Mohd Said dilahirkan pada 1907 di Gunung Semanggol, Perak. Beliau berketurunan Jawa dari kawasan Kendal, Jogjakarta. Datuknya ialah Abdul Jabbar bin Abdul Rauf yang berhijrah ke Asam Jawa, Kelang dan seterusnya berpindah ke Kuala Kurau, Perak. Bapa Ustaz Abu Bakar al-Baqir, Lebai Said merupakan seorang alim dan pendakwah kepada masyarakat setempat. Beliau berpindah ke Gunung Semanggol dan menetap di sana hingga ke akhir hayatnya. Ustaz Abu Bakar al-Baqir menimba ilmu formal semenjak berusia enam tahun di Sekolah Melayu Gunung Semanggol sehingga darjah lima. Pada ketika itu, darjah lima merupakan kelas tertinggi pada peringkat sekolah rendah dan Sekolah Melayu Gunung Semanggol merupakan sekolah kerajaan yang terawal pada ketika itu.

${ }^{1}$ Setelah itu, Ustaz Abu Bakar al-Baqir melanjutkan pelajarannya ke Pondok al-Rahmaniah selama enam tahun iaitu dari 1919 hingga 1924 bagi peringkat pendidikan rendah. ${ }^{2}$ Di sini beliau berguru dengan Ustaz Abdul Rahman, individu yang banyak mempengaruhi pemikiran Ustaz Abu Bakar al-Baqir kerana latar belakang Ustaz Abdul Rahman yang terdedah kepada pemikiran islah di Universiti al-Azhar dan pengajiannya di Mekah. ${ }^{3}$ Ustaz Abu Bakar al-Baqir turut melanjutkan pendidikan menengahnya di Madrasah Dairatul Ma' arit Wataniah di Kepala Batas, Seberang Perai Utara. Beliau belajar selama enam tahun di bawah Syeikh Abdullah Fahim yang berkelulusan dari Masjidil Haram, Mekah. ${ }^{4}$

Di madrasah ini, Ustaz Abu Bakar al-Baqir berdamping rapat dengan tokoh ulama terkenal tanah air iaitu Syeikh Abdullah Fahim yang juga merupakan penggerak utama Madrasah Dairatul Ma'arif Wataniah. Syeikh Abdullah Fahim merupakan ulama yang berpengetahuan luas dalam bidang ilmu Falak, bahasa Arab, Tafsir al-Quran dan hadis. Kepintaran dan bakat Ustaz Abu Bakar al-Baqir menarik minat Syeikh Abdullah Fahim untuk melantik beliau menjadi Ketua Muta'laah (Ketua Umum) bagi memimpin pelajar madrasah Dairatul Ma'arit Wataniah, Kepala Batas. Syeikh Abdullah Fahim turut memberi gelaran al-Baqir kepada beliau yang bermaksud 'Yang Pintar. ${ }^{5}$ Ustaz Abu Bakar al-Baqir mula terlibat dengan dunia pendidikan 
apabila mengikuti Syeikh Abdullah Fahim mengajar di Madrasah Idrisiyyah, Bukit Chandan, Kuala Kangsar pada 1930. Ketika itu, mudir madrasah ini dipimpin oleh Syeikh Abdullah al-Maghribi dari Mekah dan beliau membawa idea pemikiran islah ke madrasah ini. Pemikiran islah bermaksud satu pemikiran untuk memperbaiki masyarakat agar kembali kepada ajaran Islam sebenar sebagai satu cara kehidupan. Hasilnya, pemikiran Ustaz Abu Bakar al-Baqir turut terarah kepada corak pemikiran islah yang dibawa oleh Kaum Muda dengan menekankan pembaharuan dalam masyarakat. ${ }^{6}$

Ustaz Abu Bakar al-Baqir berada di madrasah itu sehingga pada 1934 dan beliau meletak jawatan untuk kembali ke Gunung Semanggol bagi mendirikan madrasah baharu. Peletakan jawatan tersebut berpunca daripada pemikiran dan pegangan Ustaz Abu Bakar al-Baqir yang tidak selari dengan pentadbiran madrasah tersebut yang keputusannya banyak dipengaruhi oleh ulama Kaum Tua yang mendampingi pihak istana. Selepas peletakan jawatan tersebut beliau mendirikan Maahad al-Ehya Asshariff pada 15 April 1934 bersamaan dengan 1 Muharam 1353 di Gunung Semanggol. ${ }^{7}$ Setelah perjalanan madrasah ini semakin stabil beliau dijodohkan dengan Fatimah Abdul Rahman, iaitu anak gurunya sendiri pada 1935. Hasil perkongsian hidupnya itu telah melahirkan empat orang anaknya iaitu Sahar Mursyid, Miskiah Fadilah, Naqibah Nu'ma dan Aniqah Rusda. ${ }^{8}$

Tokoh ulama dan pejuang kemerdekaan ini akhirnya menghembuskan nafas yang terakhir pada 13 November 1974 dengan meninggalkan legasi Maahad al-Ehya Assyariff yang masih kekal beroperasi hingga kini. Bagi mengenang jasa beliau, Sultan Nazrin Muizzudin Shah berkenan menganugerahkan Darjah Dato' Paduka Mahkota Perak (D.P.M.P) yang membawa gelaran Dato' secara anumerta kepada Ustaz Abu Bakar alBaqir sempena hari keputeraan baginda pada 5 November 2016. Anugerah tersebut diterima oleh anak Ustaz Abu Bakar al-Baqir, Puan Aniqah Rusda bagi pihak beliau. ${ }^{9}$ 


\section{PERJUANGAN USTAZ ABU BAKAR AL-BAQIR SEBAGAI ULAMA ISLAH}

Ustaz Abu Bakar Baqir merupakan seorang ulama pembaharuan atau reformis yang disegani oleh masyarakat. Beliau bukan hanya berjaya membangunkan Maahad al-Ehya Assyariff tetapi juga merupakan seorang insan yang sangat mengambil berat hal ehwal masyarakat di sekelilingnya, terutama yang melibatkan pendidikan dan ekonomi. Ustaz Abu Bakar Baqir sering mengingatkan masyarakat tentang tanggungjawab yang harus dipikul oleh umat Islam dengan meneruskan kembali tradisi perjuangan nabi, para sahabat dan tidak lupa menunaikan kewajipan terhadap Islam yang sebenarnya. Dengan hanya hidup berlandaskan Islam sahajalah, umat Islam akan mencapai kemajuan dan menjadi umat yang sangat disegani. ${ }^{10}$

Ustaz Abu Bakar al-Baqir mendapati banyak kegiatan orang Melayu pada ketika itu menghalang kemajuan dan bercanggah dengan ajaran Islam. Kegiatan yang bercampur aduk antara agama, adat dan khurafat itu boleh membantutkan kemajuan umat Islam. Justeru, beliau cuba membetulkan masyarakat melalui kemajuan pendidikan dengan mendirikan maahad yang diharap mampu mendidik masyarakat agar kembali kepada Islam. Pada awal abad ke-20, perkembangan menuntut kemerdekaan begitu kuat melanda di negara seperti yang berlaku di Mesir, India dan Indonesia. Sejak tahun 1934 hingga 1958, Ustaz Abu Bakar al-Baqir turut mengundang guru-guru yang mempunyai latar belakang aliran pendidikan Timur Tengah, India dan Sumatera Barat yang sangat terkenal dengan fahaman islah ataupun beraliran Kaum Muda. ${ }^{11}$ Guru-guru yang bersama-sama dengan gerakan kemerdekaan di negara berkenaan akhirnya menyebarkan semangat kemerdekaan tersebut kepada anak-anak murid di Maahad al-Ehya Asshariff. Oleh itu, tidak hairanlah Ustaz Abu Bakar al-Baqir turut dianggap sebagai tokoh ulama Kaum Muda atau reformis di Tanah Melayu ketika itu. Beliau juga mendorong mengembangkan aliran tersebut di maahad berkenaan hingga menjadi pusat pengkaderan pejuang-pejuang kemerdekaan.

Bersesuaian dengan pemikiran Kaum Muda yang ingin memodenkan sistem madrasah di Tanah Melayu, Ustaz Abu Bakar al-Baqir membuat beberapa pembaharuan dengan mendirikan sistem madrasah yang lebih 
maju hasil penelitian beliau yang suatu masa dahulu pernah menuntut di pondok juga. Beliau memperkenalkan mata pelajaran moden di maahadnya. Selain itu, beliau juga menyediakan kokurikulum yang bersepadu seperti mewujudkan kelab drama, pidato dan nasyid. Inisiatif ini membolehkan potensi pelajar itu digilap dan menjadikan mereka lebih berketerampilan dalam pelbagai aspek kehidupan. ${ }^{12}$ Sebahagian daripada mereka berjaya melanjutkan pelajaran ke Kaherah, Beirut, Mekah dan India. Di sana para pelajar ini bertemu dengan gerakan Islam, gerakan kebangsaan dan islah hingga mempengaruhi pemikiran mereka. ${ }^{13}$ Akhirnya apabila pulang ke tanah air, mereka menjadi mata rantai perjuangan pembaharuan hingga digelar Kaum Muda oleh masyarakat Melayu ketika itu.

\section{USTAZ ABU BAKAR AL-BAQIR SEBAGAI ULAMA DAN PENGGERAK KESEDARAN KEMERDEKAAN}

Sumbangan Ustaz Abu Bakar al-Baqir yang paling bermakna adalah membina semangat kebangsaan para pelajarnya melalui sistem pendidikan maahad yang diperkenalkannya. Di samping memberi pendidikan secara formal, para pelajar diasuh untuk terlibat dalam kegiatan kokurikulum. Kegiatan pelajar meliputi syarahan, perbahasan, penulisan dan kegiatan bersama-sama masyarakat kampung. Mereka turut mengadakan kempen penerangan tentang Maahad al-Ehya Assyariff untuk menambahkan pengalaman berdamping dengan masyarakat sekeliling. Para pelajar yang terdedah dengan pergolakan yang berlaku dalam masyarakat dapat merasai denyut nadi kesusahan mereka dan secara tidak langsung timbul keinsafan dan kesedaran untuk membela tanah air. ${ }^{14}$

Di maahad tersebut, Ustaz Abu Bakar Baqir turut menggalakkan para pelajarnya berkecimpung dalam dunia penulisan dan penerbitan. Para pelajarnya berjaya menerbitkan majalah berkala untuk maahad berkenaan. Ustaz Abu Bakar menggalakkan kesedaran kemerdekaan dengan menerbitkan majalah al-Ihya pada Februari 1947 di bawah kelolaan Lembaga Pustaka al-Ihya. Selain itu, maahad ini juga menerbitkan Suara Am. Dalam majalah al Ihya yang pertama terdapat artikel tentang "Merdeka, Satu Pengertian." Apa yang lebih menarik, majalah ini secara terbuka 
mengkritik golongan istana. Moto majalah berkenaan adalah "Kerosakan Negara Disebabkan Raja, Kerosakan Raja Kerana Kerosakan Ahli."15 Keberanian majalah al-Ihya meletakkan moto sebegitu bertitik tolak hasil daripada kesedaran dan pengamatan warganya terhadap kegagalan pemerintah dalam menjaga kedudukan agama, bangsa dan negara. Melalui majalah ini Ustaz Abu Bakar al-Baqir mula menyemai semangat kesedaran kemerdekaan kepada para pelajarnya agar Tanah Melayu bebas daripada belenggu feudalisme yang tidak membantu kebajikan orang Melayu. Majalah ini banyak menegur dan mengkritik sultan, ulama dan pembesar negeri yang tidak mahu berusaha menjaga kebajikan orang Melayu. Majalah al-Ihya banyak menyuarakan pandangan sinis terhadap ulama-ulama tua yang berada di belakang sultan yang tidak banyak membantu kemajuan umat Islam. Hasil inspirasi majalah ini menjadikan Maahad al-Ehya Assyariff akhirnya menjadi markas politik yang hebat hingga tertubuhnya parti Hizbul Muslimin. Walau bagaimanapun, majalah yang diterbitkan dengan 1000 cetakan itu hanya bertahan tiga keluaran sahaja kerana mengalami kerugian ekoran kegagalan promosi penjualan. ${ }^{16}$

Selain itu, Ustaz Abu Bakar turut memberi kesedaran kebangsaan melalui kitab-kitab yang diajar dalam silibus pendidikan di Maahad alEhya Assyariff seperti kitab Sirah Nabi. Pengajaran yang berdasarkan kitab-kitab ini mengupas kepentingan negara yang memerlukan perjuangan yang berorganisasi dan berkorban demi memajukan tanah air, agama dan bangsa. ${ }^{17}$ Buku Sirah Nabi ini mendapat perhatian pemerintah dan sering kali siasatan dilakukan ke atas buku ini. Namun ketika siasatan dilakukan, buku ini disembunyikan dan dikatakan hanya menggunakan buku sejarah biasa yang berjudul Judul Yakin (Kisah) iaitu kronologi Nabi Muhammad SAW. ${ }^{18}$ Pada akhir 1930-an, Ustaz Abu Bakar al-Baqir berjaya menyedarkan para pelajarnya erti semangat kemerdekaan. Pengaruh beliau begitu ketara apabila ramai pelajar Maahad al-Ehya Assyariff dari kelas Kismul al-Ali dan Tagashus masuk ke dalam Kesatuan Melayu Muda (KMM) untuk melawan penjajah bagi mendapatkan kemerdekaan penuh. Kegiatan Ustaz Abu Bakar yang aktif dalam kesatuan termasuk berdamping dengan tokoh-tokoh besar KMM seperti presidennya, Ibrahim Haji Yaakub dan Mustafa Hussein selaku penolong presidennya menyebabkan para pelajarnya juga cenderung untuk terlibat secara langsung tanpa sekatan daripada pihak pentadbiran 
maahad. Penglibatan mereka bukan sekadar sebagai ahli biasa tetapi juga sebagai pimpinan Kesatuan Melayu Muda cawangan Gunung Semanggol yang ditubuhkan pada Februari 1940. Antara para pelajar yang menjadi jawatankuasanya adalah seperti Ustaz Osman Hamzah yang menjadi Naib Yang Dipertua KMM cawangan Gunung Semanggol. ${ }^{19}$ Sabri bin Abdul Kadir sebagai Setiausaha, manakala Ahmad Yusuf@Ahmad Mahir, Yahya Nasir, Haji Abdullah, Abad Kaisar dan Kassim Muhammad menjadi ahli jawatankuasa KMM di cawangan berkenaan. ${ }^{20}$

Penubuhan KMM cawangan Maahad al-Ehya Assyariff ini mendapat galakan secara langsung daripada Ibrahim Yaakub yang sering melawat maahad ini dan beberapa tempat di sekitar Gunung Semanggol untuk melebarkan pengaruh KMM dalam kalangan masyarakat. Selama wujudnya badan ini di Maahad al-Ehya Asshariff, jawatankuasanya telah mengadakan mesyuarat sebanyak tiga kali termasuklah mesyuarat penubuhannya. Dua mesyuarat yang lain itu lebih merupakan pakatan untuk memperluas pengetahuan masyarakat tentang KMM dan satu lagi mesyuarat mengalualukan kedatangan Ibrahim Yaakub ke Maahad al-Ehya Assyariff. Peranan mereka di Maahad al-Ehya Assyariff adalah untuk berkempen secara sembunyi kepada para pelajar dan masyarakat sekeliling. Selain itu, kempen mereka juga sering menggalakkan bangsa Melayu membantu bangsa mereka dalam perniagaan dan menggalakkan masyarakat memberikan pendidikan kepada anak-anak bangsa untuk kemajuan. Kegiatan para pelajar ini kurang menimbulkan kecurigaan kerana mereka bergerak dalam masyarakat atas nama mengutip derma kebajikan untuk kemajuan Maahad al-Ehya Assyariff. Walaupun pelajar ini terpaksa berbasikal ke tempat-tempat yang jauh tetapi kempen mereka ini amat menggalakkan kerana masyarakat banyak membantu memberi sumbangan dan pada masa yang sama risalah KMM dapat disampaikan kepada masyarakat. Kempen-kempen ini juga menggalakkan masyarakat menghantar anak-anak mereka ke Maahad alEhya Assyariff. ${ }^{21}$

Kemampuan Ustaz Abu Bakar al-Baqir mentarbiah para pelajarnya dengan semangat pendidikan Islam dan anti-penjajah memudahkan kesedaran politik itu timbul dalam kalangan pelajar dan seterusnya mereka membawa kesedaran itu kepada masyarakat. Hal ini menjadikan KMM 
mudah diterima dan pengaruh tersebut pantas menyusup dalam masyarakat. Penyertaan para pelajar dalam gerakan ini bukan sekadar menjadi ahli tetapi turut menjadi pemimpin apabila Kesatuan Melayu Muda cabang Gunung Semanggol atau seluruh Perak Utara ditubuhkan. Antara pelajar yang dilantik menjadi jawatankuasa cawangan yang ditubuhkan pada Februari 1940 ialah Ustaz Osman Hamzah sebagai Naib Yang Dipertua dan Sabri Abdul Kadir sebagai Setiausaha dan ahli-ahli biasa yang menjadikan cawangan Kesatuan Melayu Muda Gunung Semanggol seramai kira-kira 40 orang. Namun begitu, penyertaan mereka tidaklah hingga mengorbankan kepentingan pengajian mereka. Hanya seorang dua daripada mereka ini yang benar-benar berjuang seperti Osman Hamzah dan Sabri Abdul Kadir. ${ }^{22}$ Kedudukan Maahad al-Ehya Assyariff sebagai pusat kegiatan KMM yang utama di Perak diakui oleh Ibrahim Yaakub sendiri yang menegaskan bahawa Maahad al-Ehya Assyariff telah wujud cawangan KMM sebelum diikuti oleh Sitiawan dan tempat-tempat lain. ${ }^{23}$

Semasa Jepun menduduki Tanah Melayu, Dr. Burhanuddin al-Helmy sering datang ke Maahad al-Ehya Asshariff. Beliau merupakan pegawai tinggi Jepun dalam hal ehwal agama Islam di markas Taiping yang sering memberi semangat kesedaran kemerdekaan kepada para pelajar. Hal ini mendorong Ustaz Abu Bakar lebih bersemangat kerana dengan adanya Dr. Burhanuddin, maahadnya dapat berjalan dengan lancar tanpa gangguan daripada Jepun. Penglibatan Ustaz Abu Bakar al-Baqir terserlah apabila beliau bersama-sama dengan Ibrahim Yaakub yang ketika itu merupakan Leftenan Kolonel Pasukan Pembela Tanah Air (PETA), Dr. Burhanuddin, Pak cik Ahmad, Hanif Sulaiman serta pegawai Jepun dari Singapura dan Tokyo turut berbincang di sebuah rumah pegawai tinggi Jepun di Taiping pada 8 Ogos 1945 untuk penyerahan kemerdekaan bersama dengan kemerdekaan Indonesia. ${ }^{24}$

Kedatangan British semula ke Tanah Melayu pada 12 September 1945 menyemarakkan lagi semangat perjuangan orang Melayu kerana kedatangan imperialisme kali kedua ini lebih agresif lagi dengan cuba untuk menghapuskan hak-hak Melayu seperti menyamaratakan hak kewarganegaraan dan menghilangkan kedudukan sultan melalui penubuhan Malayan Union. Tindakan British ini merupakan manifestasi kemarahan 
mereka kepada sebahagian besar orang Melayu yang memberi sokongan kepada Jepun ketika menentang British di Tanah Melayu. Orang Melayu menubuhkan Parti Kebangsaan Melayu Malaya (PKMM) pada 17 Oktober 1945 untuk menentang kembali penjajahan British tersebut. Parti ini ditubuhkan di Ipoh dan Mokhtaruddin Laso merupakan presiden pertama parti berkenaan. ${ }^{25}$ Timbalan Presiden PKMM pula ialah Dr. Burhanuddin yang ketika itu berada di Singapura. Dr. Burhanuddin memimpin sepenuhnya PKMM apabila Mokhtaruddin Laso menghilangkan diri dari Tanah Melayu. ${ }^{26}$ Semasa Dr. Burhanuddin memimpin PKMM, Ustaz Abu Bakar al-Baqir yang mempunyai hubungan baik dengan beliau sering menjemputnya datang ke Maahad al-Ehya Assyariff. ${ }^{27}$ Ustaz Abu Bakar alBakir menggunakan kesempatan ini untuk bekerjasama demi kepentingan Islam. Beliau mendapati kerajaan melalui jabatan agama Islam, sultan dan UMNO kurang memberi perhatian serius terhadap kemajuan umat Islam. Maahad al-Ehya Assyariff mula terlibat dengan politik secara langsung pada 1947 setelah benih-benih politik berkembang subur di maahad berkenaan. Guru-guru yang terdedah dengan gerakan reformis dan Kaum Muda menyemai semangat berkenaan kepada para pelajar melalui pendidikan yang disampaikan di dalam kelas, aktiviti-aktiviti kokurikulum dan kegiatan masyarakat di luar maahad. Melalui penerbitan majalah al-Ehya, semangat kesedaran kemerdekaan disalurkan kepada para pelajar dan masyarakat setempat yang berada di sekitar Gunung Semanggol.

\section{USTAZ ABU BAKAR AL-BAQIR DAN PENUBUHAN HIZBUL MUSLIMIN}

Pada 22 Mac 1947 di Maahad al-Ehya Assyariff telah diadakan satu persidangan ulama dan terdapat tiga resolusi yang penting iaitu menubuhkan Pusat Perekonomian Melayu Se-Malaya (PERPEMAS), Lembaga Pendidikan Rakyat (LEPIR) dan Majlis Agama Tertinggi Malaya (MATA). Dato Onn menjadi bimbang dengan pengaruh MATA dan PEMERMAS yang boleh menggantikan peranan yang didominasi oleh UMNO terhadap masyarakat Melayu di samping kegusaran beliau terhadap pengaruh PKMM terhadap Maahad al-Ehya Assyariff. Kegusaran Dato Onn bertambah nyata apabila MATA melihat perlunya ditubuhkan satu 
parti Islam untuk mengembalikan kedaulatan agama di Tanah Melayu. ${ }^{28}$ MATA melihat majlis agama Islam negeri gagal berperanan kerana wujud beberapa sekatan yang menghalang kebangkitan dan kesedaran bangsa. Sekatan itu wujud disebabkan unsur campur tangan pihak istana. ${ }^{29}$ Untuk itu, MATA berhasrat untuk membentuk parti Islam sebagaimana Masjumi di Indonesia. Pada 23 Februari 1948, terbentuklah satu panitia untuk mengadakan kongres parti Islam kali ke-2 pada 13 dan 14 Mac 1948. Pada hari pertama persidangan tersebut diadakan upacara Maulud Nabi, dibacakan ucapan-ucapan tahniah dan doa selamat termasuk daripada Menteri-menteri Besar seperti Perak, Johor, Kelantan, Terengganu dan Selangor. Pada hari kedua dibuka dengan nyanyian lagu Masjumi untuk menaikkan semangat ahli kongres dan ucapan pidato. ${ }^{30}$

Persidangan yang dihadiri kira-kira 4,500 orang itu dengan 50 wakil-wakil badan pergerakan akhirnya bersetuju menubuhkan Parti OrangOrang Islam Semalaya atau dikenali sebagai Hizbul Muslimin. Nama ini dicadangkan oleh Ustaz Abu Bakar sendiri dengan disokong oleh Ustaz Abrab Tamimi dan Dr. Burhanuddin. Dasar Hizbul Muslimin ini adalah mencapai kemerdekaan bangsa Melayu yang berdaulat dengan mewujudkan Tanah Melayu Darul Islam. Akhirnya, Hizbul Muslimin ditubuhkan hasil satu resolusi Kongres MATA pada hari kedua bersamaan 14 Mac 1948. ${ }^{31}$

Pada 30 April 1948, British mengeluarkan satu laporan tentang Hizbul Muslimin ini. Menurut pekeliling tersebut, Hizbul Muslimin mahu menjadikan Tanah Melayu mencapai kemerdekaan, mewujudkan PanIslamisme dan seterusnya menjadikan Tanah Melayu sebagai Darul Islam. ${ }^{32}$ Kegusaran British tersebut semakin nyata apabila melihat Hizbul Muslimin bergerak pantas menyebarkan pengaruhnya dengan menubuhkan cawangan ke seluruh semenanjung dalam masa tiga bulan sahaja. Walaupun ketika itu tiada kemudahan sistem telekomunikasi dan sistem pengangkutan sebaik hari ini tetapi pengaruh Hizbul Muslimin melangkau beberapa buah negeri seperti Johor, Melaka, Negeri Sembilan, Selangor, Kelantan, Terengganu, Pulau Pinang, Kedah dan juga Perlis. Di Johor pada 10 Mei 1948, Hizbul Muslimin tertubuh di Kluang, Johor yang dipimpin oleh Ustaz Othman bin Rahimin selaku Presiden dan Timbalan Presidennya pula ialah Imam Mahmud bin Yussof. Wakil Hizbul Muslimin dari Gunung Semanggol, 
Ustaz Asri Abdullah Salleh telah memberi ucapan dalam mesyuarat tersebut bahawa Hizbul Muslimin akan terus menuntut kemerdekaan dan tidak gentar dengan ugutan $\mathrm{UMNO}{ }^{33}$

Selain berkempen ke Johor, Ustaz Abu Bakar al-Baqir juga turut melawat Melaka, Negeri Sembilan dan Selangor untuk mewujudkan cawangan di sana. Di Melaka, Haji Ahmad bin Harun menjadi presiden cawangan Hizbul Muslimin apabila parti itu ditubuhkan pada 20 April 1948. Dalam siri kempennya di Melaka, Ustaz Abu Bakar menegaskan penubuhan Hizbul Muslimin ini adalah untuk menuntut kemerdekaan. Beliau berjaya menubuhkan cawangan Hizbul Muslimin di Melaka pada 20 April 1948. Hizbul Muslimin cawangan Melaka dipimpin oleh Haji Ahmad bin Harun selaku presiden. Ketika menyampaikan ucapan di Melaka, Ustaz Abu Bakar al-Baqir menegaskan bahawa aliran terkini dalam aktiviti politik di seluruh dunia menunjukkan bahawa orang ramai mula menuntut kemerdekaan. Keadaaan tersebut juga merupakan punca penubuhan Hizbul Muslimin kerana kemunculannya dapat meningkatkan tuntutan terhadap hak-hak mereka. Beliau juga menegaskan bahawa kehancuran Hizbul Muslimin juga menandakan kejatuhan agama Islam. ${ }^{34}$

Dari Melaka, Ustaz Abu Bakar al-Baqir berkempen ke Ulu Gadong, Negeri Sembilan pada 20 April 1948 sambil melawat Madrasah Ittihadiyyah. Di samping itu, Ustaz Abu Bakar al-Baqir juga dilaporkan mengadakan perbincangan sulit dengan Haji Mohamed Yatim, salah seorang ahli jawatankuasa madrasah tersebut berkenaan tujuan penubuhan Hizbul Muslimin. ${ }^{35}$ Pada 24 April 1948 pula, Ustaz Abu Bakar al-Baqir tiba di Lenggeng, Negeri Sembilan. Beliau hadir untuk merasmikan penubuhan Hizbul Muslimin di kawasan berkenaan. Mesyuarat tersebut turut dihadiri oleh ahli PKMM, PETA dan Persatuan Indonesia Merdeka (PIM). ${ }^{36}$ Satu keputusan juga dicapai di akhir mesyuarat tersebut untuk menubuhkan cawangan Hizbul Muslimin di Lenggeng selain cadangan menubuhkan cawangan Hizbul Muslimin di seluruh Negeri Sembilan.

Setelah itu, Ustaz Abu Bakar al-Baqir bergerak ke Selangor pula. Mesyuarat penubuhan cawangan dan pelantikan ahli jawatankuasa tersebut dilakukan di Sekolah Arab, Kajang pada 24 April 1948. Antara yang hadir 
ialah Raja Idris selaku Penghulu Kajang. Tuan Haji Arshad, Kadi Lenggeng, Negeri Sembilan dan 35 orang perempuan AWAS. Keputusan mesyuarat sebulat suara melantik Ustaz Mohamed Sasi Hizbul untuk memimpin Hizbul Muslimin cawangan Selangor. Dalam ucapan mesyuarat tersebut, Ustaz Abu Bakir menegaskan orang Melayu jauh ketinggalan dalam serba bidang manakala guru-guru agama kurang berperanan dalam memberi penerangan agama. ${ }^{37}$

Pada 11 Mei 1948 cawangan Hizbul Muslimin di Tanjong Karang juga berjaya ditubuhkan di bawah pimpinan Haji Rahmad bin Haji Jailani selaku Presiden dan Omar bin Kiyai Marzuki selaku Timbalan Presiden. Dalam mesyuarat penubuhan cawangan tersebut kira-kira 115 orang hadir untuk menjayakan penubuhan parti berkenaan. ${ }^{38}$ Bilangan tersebut merupakan satu jumlah yang besar bagi sebuah parti yang baharu ditubuhkan tanpa bantuan promosi daripada alat sebaran media. Setiausaha Hizbul Muslimin, Yunus bin Yatimi yang juga merupakan Ketua Propaganda API cawangan Selangor pernah memegang jawatan yang sama dalam PKMM. Beliau menyeru kepada golongan ulama dan pihak berwajib agar bangkit secara aktif dalam bidang politik. ${ }^{39}$

Pada 2 Mei 1948 Ustaz Abu Bakar al-Baqir pergi ke Kedah untuk menubuhkan cawangan Hizbul Muslimin di Kedah, namun beliau gagal mendapatkan sokongan Hj Hussin bin Che Dol, Presiden Persatuan GuruGuru Agama. ${ }^{40}$ Setelah itu Ustaz Abu Bakar al-Baqir pergi ke Terengganu dan pada 14 Mei 1948 beliau tiba di Kemaman, Terengganu. Ketika itu beliau disambut oleh Abu Bakar Mohamed Amin yang merupakan Presiden PKMM cawangan Terengganu. Ketika menyampaikan ucapan di sebuah masjid, Ustaz Abu Bakar al-Baqir menegaskan bahawa semua umat perlu bersatu. Beliau menegaskan meskipun segelintir pihak beranggapan perjuangan politik Hizbul Muslimin di pihak kiri atau sebaliknya, tujuan utama penubuhan Hizbul Muslimin ialah untuk menyatukan UMNO dan PKMM. Pada 15 Mei 1948, Ustaz Abu Bakar tiba di Kuala Terengganu dan berucap di bangunan ibu pejabat PKMM. Beliau mengkritik UMNO kerana gagal membantu orang Melayu. Bagi beliau, penubuhan Persekutuan Tanah Melayu hanyalah perangkap dan usaha menghalang penubuhan Persekutuan Tanah Melayu hanya boleh dibuat melalui kerjasama dengan PKMM. ${ }^{41}$ 
Pada 16 Mei 1948, Ustaz Abu Bakar al-Baqir tiba di Besut, Terengganu untuk menghadiri perhimpunan yang dihadiri 300 orang hadirin di Kampung Raja. Dalam ucapannya, beliau menegaskan bahawa UMNO, PKMM dan Hizbul Muslimin sepatutnya bersatu bagi mencapai kebebasan. Kehadiran beliau ke Besut juga turut mendapat sokongan Naib Kadi Besut, Abu Bakar Mohamed Amin yang juga merupakan Presiden PKMM cawagan Terengganu. Dalam ucapannya, beliau mengatakan bahawa meskipun beliau pernah berkhidmat sebagai pegawai kerajaan dan menduduki jawatan penting, beliau memutuskan untuk melepaskan jawatan dalam kerajaan kerana beliau begitu marah terhadap tindakan penjajah yang telah menghapuskan kebebasan orang Melayu. ${ }^{42}$

Di Pahang pula rombongan Ustaz Abu Bakar al-Baqir menubuhkan cawangan di Raub iaitu kawasan yang menjadi pusat kegiatan golongan radikal. Majlis penubuhan tersebut dihadiri 120 orang dan dipengerusikan oleh Ustaz Umar al-Farouk, bekas pelajar Maahad al-Ehya Assyariff. Jawatankuasa Hizbul Muslimin cawangan ini dibentuk dengan mandat diberikan kepada Tuan Haji Mohd Araof sebagai pengerusi manakala setiausahanya ialah Ustaz Hashim dan bendaharinya ialah Cikgu Lia. ${ }^{43}$ Pada 18 Mei 1948, Ustaz Abu Bakar al-Baqir melebarkan sayap Hizbul Muslimin ke Kelantan. Beliau menyampaikan ucapan di Kota Bharu, Kelantan dan menegaskan bahawa Tanah Melayu merupakan sebuah negara yang kaya namun kekayaan tersebut tidak dapat dinikmati oleh penduduk Tanah Melayu. Sebaliknya dibolot oleh golongan penjajah. Dalam program jelajah untuk memberi kesedaran kemerdekaan kepada orang Melayu, Ustaz Abu Bakar al-Baqir juga merasmikan penubuhan cawangan Hizbul Muslimin di Kampung Machang dan di Kota Bharu, Kelantan. Haji Ismail bin Hj Yusoff dilantik sebagai Presiden Hizbul Muslimin cawangan Kota Bharu, Kelantan. Pada 21 Mei 1948, Ustaz Abu Bakar al-Baqir telah meninggalkan Kota Bharu dan menuju ke Besut, Terengganu sekali lagi untuk bermesyuarat di sana pada 23 Mei 1948. Pada 2 Jun 1948, Utusan Melayu melaporkan ucapan Ustaz Abu Bakar al-Baqir yang mengatakan bahawa masyarakat Melayu akan mencapai kemerdekaan dalam tempoh sepuluh tahun. Jika ramalan Ustaz Abu Bakar itu diteliti, ramalannya adalah tepat kerana Tanah Melayu akhirnya mencapai kemerdekaan pada 1957 iaitu kira-kira sembilan tahun daripada ucapan beliau. ${ }^{44}$ 
Di Pulau Pinang pada 4 Jun 1948 sempena sambutan Israk Mikraj di Balik Pulau, Ustaz Abu Bakar al-Baqir telah mencadangkan penubuhan cawangan Hizbul Muslimin Pulau Pinang, namun tidak mendapat sambutan. Di Perak sendiri, sudah pastilah Hizbul Muslimin paling berpengaruh kerana Maahad al-Elya Assyariff merupakan pusat penubuhan Hizbul Muslimin. Malah di maahad ini, Bahagian Belia Hizbul Muslimin berjaya ditubuhkan di Maahad al-Ehya al-Syariff pada 5 Jun 1948. Lebih daripada 200 perwakilan daripada pelbagai pertubuhan belia di seluruh Tanah Melayu menghadiri perhimpunan tersebut. Mesyuarat bahagian belia telah dipengerusikan oleh Mohammed Asri yang merupakan bekas pelajar dan guru di maahad berkenaan dan dihadiri Presiden Hizbul Muslimin, Ustaz Abu Bakar al-Baqir. ${ }^{45}$

Untuk menegaskan Hizbul Muslimin bukan mengancam keselamatan negara, maka pada 28 Julai 1948 Ustaz Abu Bakar al-Baqir menulis surat kepada Pesuruhjaya Jeneral British. Beliau menyatakan bahawa Hizbul Muslimin merupakan sebuah parti politik yang berasaskan agama Islam dan perjuangannya adalah melalui jalan keamanan mengikut saluran undang-undang negara. Ustaz Abu Bakar al-Baqir menegaskan bahawa tujuan utama penubuhan Hizbul Muslimin adalah bagi membangkitkan keadaan sosial orang Melayu yang beragama Islam, selain meluaskan pemahaman mereka terhadap agama. ${ }^{46}$ Namun begitu, bagi British Hizbul Muslimin boleh mengancam keselamatan kerana dikawal oleh komunis dari Indonesia dan parti ini turut mendapat dana dari Masyumi untuk meluaskan pengaruh mereka di Tanah Melayu. British bimbang, perjuangan politik bercorak agama yang diperjuangkan oleh Hizbul Muslimin mampu menarik sokongan orang Melayu dari pelbagai kelas termasuk daripada PKMM dan juga UMNO. ${ }^{47}$

Disebabkan pengaruh Hizbul Muslimin begitu cepat berkembang di beberapa negeri di Tanah Melayu, pada 29 Julai 1948 British menangkap beberapa pemimpin tertinggi Hizbul Muslimin. Antara yang ditangkap ialah Ustaz Abu Bakar al-Baqir, Ustaz Abdul Rab Tamimi bin Sulaiman (Ketua Propaganda Hizbul Muslimin) dan Ustaz Abdul Rauf bin Ahmad. ${ }^{48}$ British menangkap mereka kerana dikatakan sebagai musuh kerajaan dan musuh raja-raja yang terkenal. Malah, mereka terlibat dalam hampir semua 
organisasi politik berhaluan kiri. Penangkapan Ustaz Abu Bakar al-Baqir dan rakan-rakannya itu menyebabkan Hizbul Muslimin berkubur. ${ }^{49}$ Namun begitu, perjuangan menuntut kemerdekaan dan cita-cita membentuk daulah Islam tidak terhenti. Pada 1951 bekas anak muridnya di Maahad al-Ehya Assyariff, Ustaz Ahmad Fuad bin Hassan mendapat inspirasi menubuhkan Parti Islam se-Malaya sebagai kesinambungan daripada perjuangan Hizbul Muslimin yang diharamkan oleh British.

\section{PERJUANGAN USTAZ USTAZ ABU BAKAR AL-BAQIR PASCA TAHANAN DARURAT}

Setelah Ustaz Abu Bakar al-Baqir terpenjara selama empat tahun, beliau dibebaskan daripada tahanan politik di Kamunting, Taiping pada bulan Oktober 1952 secara bersyarat. Setelah keluar dari penjara, perjuangan politik beliau tidak terhenti walaupun menghadapi sekatan politik. Namun begitu, Ustaz Abu Bakar al-Baqir menukar strategi beliau dengan tidak melibatkan diri secara aktif dalam politik. Jika melibatkan diri semula dalam politik secara aktif, beliau boleh didakwa semula ke penjara. Justeru, beliau terpaksa mengurangkan kegiatan politiknya atas faktor strategi iaitu untuk mengelak daripada menjadi bahan intipan mata-mata British selepas dibebaskan. Selain itu, keutamaan perjuangannya selepas dibebaskan adalah untuk membangunkan kembali Maahad al-Ehya Assyariff yang menghadapi situasi suram ekoran menghadapi masalah kewangan dan kekurangan pelajar. ${ }^{50}$ Kekurangan yang semakin menjadi-jadi tersebut adalah disebabkan oleh rasa bimbang ibu bapa terhadap keselamatan anak-anak mereka yang sering dipantau pihak berkuasa yang menganggap maahad tersebut terlibat dengan gerakan yang berbahaya. Mereka turut curiga dengan kegiatan berbau politik yang melibatkan para pelajar dan guru-guru di maahad tersebut. Selain itu, kekurangan guru-guru berkaliber kerana ditangkap atau sebahagian daripada mereka berhenti bekerja pula ekoran maahad turut mengalami masalah kewangan. Masyarakat tidak lagi memberi derma ekoran bimbang ditangkap kerana memberi sokongan kepada maahad berkenaan..$^{51}$ Pada masa yang sama, madrasah-madrasah yang bebas politik seperti Idrisiah, Diniah dan Yahyawiyah menjadi saingan dan tempat yang kondusif bagi para pelajar ini meneruskan pengajian. Orang Melayu juga 
mula mempunyai kesedaran untuk menghantar anak-anak mereka ke sekolah Melayu dan Inggeris yang lebih memberi nilai ekonomi berbanding sekolah agama yang tidak mendapat perhatian kerajaan pada ketika itu. ${ }^{52}$

Untuk meredakan tekanan pemerintah terhadap Maahad al-Ehya Assyariff dan demi mendapatkan sumbangan dana daripada masyarakat, Ustaz Abu Bakar al-Baqir telah menukar pendekatan pendidikan di maahadnya yang tidak lagi berorientasikan politik. Kelas pengajaran politik yang dikendalikan oleh Mohd Asri Muda juga dibatalkan. Sikap baharu ini mendapat sambutan yang baik daripada pihak berkuasa termasuk Pejabat Agama Islam Perak, UMNO dan juga Sultan Perak ketika itu, Sultan Yussuf Izzuddin Shah. ${ }^{53}$ Bermula daripada hubungan yang baik tersebut, pejabat agama telah menyumbang $\$ 14,000$ kepada maahad berkenaan pada tahun 1953. Daripada jumlah tersebut, $\$ 6,000$ adalah bayaran tetap tahunan yang dipersetujui oleh Pejabat Agama tersebut. Sementara bakinya adalah untuk menyiapkan bangunan dan membaiki bangunan lama. ${ }^{54}$

Namun begitu, perjuangan politik Ustaz Abu Bakar al-Baqir kembali menjelma selepas tiga tahun pembebasannya apabila Pilihan Raya Persekutuan yang pertama diadakan pada 1955. Ketokohan dan populariti beliau menyebabkan beberapa parti politik seperti PAS, UMNO, Parti Kebangsaan Perak dan Perikatan Melayu Perak ingin menjadikannya sebagai calon pilihan raya yang mewakili parti mereka. Pada peringkat awal Ustaz Abu Bakar al-Baqir menolak semua tawatan parti-parti berkenaan. Beliau agak keberatan untuk menerima tawaran tersebut ekoran kebimbangannya terhadap ibu bapa para pelajar yang berlainan wadah politik dengannya tidak mahu lagi menghantar anak-anak mereka menuntut di Maahad alEhya Assyariff. Namun begitu, darah perjuangannya untuk membebaskan tanah air menuju kemerdekaan tidak pernah padam dalam sanubari beliau. Akhirnya Ustaz Abu Bakar al-Baqir memilih berjuang melalui kaedah pilihan raya. Apatah lagi pelaksanaan sistem pemilihan tampuk kepimpinan negara yang pertama tersebut dianjurkan oleh pemerintah dan satu-satunya peluang yang ada ketika itu untuk meneruskan perjuangan menuntut kemerdekaan melalui saluran demokrasi. Walaupun UMNO dan PAS menawarkan tiket untuk menjadi calon pilihan raya tersebut tetapi beliau memilih untuk mewakili Perikatan Melayu Perak. Ustaz Abu Bakar 
al-Baqir berbuat sedemikan demi menjaga hubungan beliau dengan anak murid dan orang kampungnya yang banyak menganggotai kedua-dua parti berkenaan. Di samping itu, ia juga bertujuan untuk mengelak perbalahan yang lebih kronik antara mereka jika beliau memilih salah satu daripada parti berkenaan yang sedang bersaing mencari pengaruh dalam arena politik khususnya di kawasan Gunung Semanggol. Ustaz Abu Bakar al-Baqir turut memperlihatkan sikap tidak mementingkan diri sendiri dengan tidak mahu bertanding di Parlimen Kerian sedangkan pengaruh beliau begitu kuat di kawasan tersebut terutamanya di Gunung Semanggol. Sebaliknya, beliau bertanding di kawasan Larut dan Matang yang majoritinya adalah pengundi Cina yang tidak mengenali ketokohan beliau sebagai ulama yang membangunkan Maahad al-Ehya Assyariff dan pengasas parti Islam pertama di Tanah Melayu. ${ }^{55}$

Akhirnya beliau kalah kepada calon Parti Perikatan, Dr Cheah Khay Chuan dengan undi 15,407 berbanding undi Ustaz Abu Bakar al-Baqir yang mendapat sebanyak 4,453 undi di samping dua orang lagi pencabarnya daripada Parti Kebangsaan Perak (NAP) dan Parti Buroh yang masingmasing mendapat 3,437 undi dan 761 undi. Sebaliknya di Parlimen Kerian, PAS memperoleh kemenangan pertamanya apabila Tuan Haji Ahmad Tuan Hj Husin mendapat kemenangan dengan undi 8,685 menewaskan calon Perikatan, Mohd Sulaman Haji Ahmad (Sulaiman Palestin) dengan undi 8,235 dan calon ketiga dari Parti Kebangsaan Perak dengan mendapat 3,315 undi. ${ }^{56}$ Selepas pilihan raya tersebut, Ustaz Abu Bakar al-Baqir tidak lagi terlibat dengan politik kepartian sebaliknya menjadi tempat rujukan dan perbincangan kepada pejuang-pejuang kemerdekaan seperti Dr Burhanuddin al-Helmy yang terus cenderung dalam politik sehingga Tanah Melayu mencapai kemerdekaan. Ustaz Abu Bakar al-Baqir juga berjaya melahirkan lepasan Maahad al-Ehya Assyariff yang mampu meneruskan perjuangannya seperti Profesor Zulkifli Muhammad dan Datuk Asri Muda terus berjuang dalam PAS selepas kemerdekaan untuk membentuk daulah Islam di Tanah Melayu. Walaupun Ustaz Abu Bakar al-Baqir tidaklah berjuang sehingga Tanah Melayu mencapai kemerdekaan tetapi sumbangannya sebagai penggerak kesedaran kemerdekaan kepada para pelajarnya bermula sewal 
tahun 30-an hingga pertengahan 50-an mendorong kelangsungan perjuangan kemerdekaan tersebut diteruskan oleh anak didiknya dan reformis lain. Bagi Ustaz Abu Bakar al-Baqir, keperluan yang lebih mendesak ketika itu adalah memberi tumpuan kepada pembangunan Maahad al-Ehya Assyariff yang tidak mampu diusahakan oleh sosok yang lain berbanding kegiatan politik yang lebih ramai pendukungnya. Apatah lagi tugasnya untuk menaikkan reputasi Maahad al-Ehya Assyariff yang masih tercalar teruk berada di bahunya kesan daripada kegiatan politiknya dahulu di maahad tersebut.

\section{KESIMPULAN}

Perjuangan Ustaz Abu Bakar al-Baqir, menunjukkan beliau merupakan seorang ulama yang menggunakan pentas institusi pendidikannya untuk berjuang menentang British di Tanah Melayu. Ketokohan Ustaz Abu Bakar sebagai ulama dan penggerak kesedaran kemerdekaan di Tanah Melayu begitu menonjol dengan penubuhan Maahad al-Ehya Asshariff. Melalui maahad ini beliau berjaya menggerakkan kesedaran tersebut kepada para pelajar dan masyarakat sekelilingnya hingga menimbulkan kecurigaan British dan UMNO. Mereka berusaha melumpuhkan perkembangan maahad tersebut dengan menangkap tokoh-tokoh penting yang menggerakkan maahad berkenaan. Peranan beliau sebagai pejuang kemerdekaan amat terserlah apabila Ustaz Abu Bakar al-Baqir menubuhkan parti Islam pertama di Tanah Melayu iaitu Hizbul Muslimin pada 1948. Walaupun pejuang kemerdekaan seperti Ustaz Abu Bakar al-Baqir ditangkap tetapi obor kesedaran rakyat untuk menuntut kemerdekaan tidak padam, malah menyemarakkan kegiatan politik orang Melayu. Sebagai ulama islah, beliau bukan sekadar membangunkan masyarakat Melayu dalam bidang pendidikan dan dakwah tetapi turut menggerakkan kesedaran kemerdekaan di Tanah Melayu. Sewajarnyalah sumbangan beliau sebagai ulama dan pejuang kemerdekaan dititipkan dalam lipatan sejarah sebagai tokoh ulama yang turut berjuang menuntut kemerdekaan negara. 


\section{NOTA}

1 Temu bual dengan Puan Aniqah Rusda binti Abu Bakar pada 2 November 2013, pukul 2.30 petang di rumahnya di Taman Panglima, Ipoh, Perak. Beliau merupakan anak bongsu Ustaz Abu Bakar al-Baqir.

2 Pondok ini didirikan pada 1918 oleh Ustaz Abdul Rahman, bapa mentua Ustaz Abu Bakar al-Baqir. Beliau menuntut ilmu selama 15 tahun di Asia Barat hingga berjaya memiliki kelulusan dari Universiti al-Azhar dan Masjidil Haram, Mekah. Lihat Nabir bin Haji Abdullah, Maahad Il Ihya Assyariff Gunung Semanggol 1934-1959, Kuala Lumpur, terbitan Universiti Kebangsaan Malaysia, Pencetakan Khee Meng, 1976, hlm. 34.

3 Keterangan disampaikan oleh Nabir Abdullah dalam syarahan pada Sambutan 82 tahun Al-Ehya As Syariff pada 16 April 2016 di Maahad al Ihya Assyariff Gunung Semanggol.

4 Nabir bin Haji Abdullah, Maahad Il Ihya Assyariff Gunung Semanggol 1934-1959, 1976, hlm. 34 .

5 Ibid., hlm. 35 hingga 36.

6 Saari Sungib, Tokoh-tokoh Besar Gerakan Islam dalam Sejarah, Selangor: Rijal Media, 2010 .

7 Il Ihya Assyariff, Buku Peringatan Suku Abad (sempena sambutan Jubilee Perak), November 1959, hlm. 17. Walau bagaimanapun menurut Nabir Abdullah, Ustaz Abu Bakar al-Baqir pulang ke Semanggol untuk mendidirikan Maahad al-Ihya Assyariff pada 1933 dan bukannya pada 1934. Lihat Nabir bin Haji Abdullah, 1976, Maahad Il Ihya Assyariff Gunung Semanggol 1934-1959, hlm. 36.

8 Temu bual dengan Puan Aniqah Rusda pada 2 November 2013, pukul 2.30 petang di rumahnya di Taman Panglima, Ipoh Perak.

9 Utusan Malaysia, 6 November 2016.

${ }^{10}$ Khairul Nizam Zainal Badri, Ketokohan dan Pemikiran Abu Bakar al-Baqir, Shah Alam: Karisma Publication, 2008, hlm. 50.

${ }^{11}$ Nabir bin Haji Abdullah, Maahad Il Ihya Assyariff Gunung Semanggol 1934-1959, 1976, hlm. 265-266.

${ }^{12}$ Temu bual dengan Dr. Sabri Salamon pada 27 Disember 2016 di Felda Kampung Awah, Temerloh, Pahang. Beliau merupakan bekas pelajar Maahad al-Ehya Ashariff dari tahun 1955 hngga 1959.

${ }^{13}$ Silcock \& Aziz, Nationalism in Malaya, 11 th Conference Institute of Pacific Relations, Lucknow India, October 3-15, 1950, hlm. 13.

${ }^{14}$ Temu bual dengan Dr. Sabri Salamon pada 27 Disember 2016 di Felda Kampung Awah, Temerloh, Pahang.

15 Al-Ihya, Pulau Pinang: Lembaga Pustaka al-Ihya, Persama Press, 1947, Bil 1, tahun 1.

${ }^{16}$ Nabir bin Haji Abdullah, Maahad Il Ihya Assyariff Gunung Semanggol 1934-1959, 1976, hlm. 104.

${ }^{17}$ Ustaz Abu Bakar menyedari kepentingan watan kerana beliau sendiri turut serta dalam beberapa badan seperti Kesatuan Melayu Selat (PP), Persatuan Melayu Perak, Persatuan Sun Light Taiping, Saadatul Islam. Lihat Abu Bakar al-Baqir, "Gerakan-gerakan Politik yang Berunsur atau Berkaitan dengan Ugama Islam di Malaysia” dalam Kertas Kerja Seminar ME 405-Siri Tokoh-tokoh Malaysia, Jabatan Sejarah, Universiti Kebangsaan Malaysia, 19 September 1973, hlm. 2. 
${ }^{18}$ Nabir bin Haji Abdullah, Maahad Il Ihya Assyariff Gunung Semanggol 1934-1959, 1976, hlm. 75.

${ }^{19}$ Ustaz Osman bin Hamzah merupakan bekas pelajar dan akhirnya menjadi tenaga pengajar di al-Ehya Assyariff. Beliau menggalakkan para pelajar dan kakitangan maahad tersebut terlibat dengan gerakan kemerdekaan yang diperjuangkan oleh Hizbul Muslimin. Apabila Hizbul Muslimin ditubuhkan, beliau menjadi Ketua Shabab Hizbul Muslimin. Beliau juga merupakan anggota KMM cawangan Perak yang aktif dan turut menjalin hubungan dengan pemimpin radikal Indonesia seperti Sutan Djenain. Lihat T.N Harper, The End of Empire and The Making of Malaya, Cambridge: Cambridge Universiti Press, 2001, hlm. 122.

${ }^{20}$ Nabir bin Haji Abdullah, Maahad Il Ihya Assyariff Gunung Semanggol 1934-1959, 1976, hlm. 77.

${ }^{21}$ Temu bual dengan Dr. Sabri Salamon pada 27 Disember 2016 di Felda Kampung Awah, Temerloh, Pahang. Beliau merupakan bekas pelajar Maahad al-Ehya Asshariff dari tahun 1955 hngga 1959.

${ }^{22}$ Nabir bin Haji Abdullah Maahad Il Ihya Assyariff Gunung Semanggol 1934-1959, 1976, hlm. 76.

${ }^{23}$ Keterangan disampaikan oleh Ibrahim Yaakub sewaktu soal jawab kertas kerja Ishak Hj Muhammad," Politik Tanah Melayu hingga pendudukan Jepun”. -Siri Sejarah TokohTokoh Malaysia, Jabatan Sejarah, UKM 1973. 24 /7/1973.

${ }^{24}$ Abu Bakar al-Baqir, "Gerakan-gerakan Politik Yang Berunsur atau Berkaitan dengan Ugama Islam di Malaysia”, Kertas kerja Seminar ME 405, Siri Tokoh-Tokoh Malaysia, Jabatan Sejarah, Universiti Kebangsaan Malaysia, 19 Ogos/September 1973, hlm. 4. Lihat juga Ibrahim Haji Yaakub, "Sejarah Perintis Kemerdekaan Malaysia," (bahagian kedua). Kertas kerja Seminar ME 405, Sejarah Tokoh-Tokoh Malaysia, Jabatan Sejarah, Universiti Kebangsaan Malaysia, 29 Ogos 1973. hlm. 10.

${ }^{25}$ Anak kelahiran Indonesia ini pernah ke Moscow ketika berumur 18 tahun mewakili Kongres Komunis bagi mewakili Indonesia. Beliau ke Singapura sebagai pemberita bagi akhbar Indonesia. Terlibat sebagai Malayan Communist Party (MCP) dan menjadi ketua 'Anti-Japanese Union'. PKMM dianggap parti yang radikal untuk menentang British. Lihat G.P. Means, Malayan Political, University of London Press Ltd, London, 1970, hlm. 53.

${ }^{26}$ Ramai kawannya dalam PKMM mengatakan beliau balik ke Indonesia kerana berjuang menentang tentera Belanda yang tidak mengiktiraf kemerdekaan Indonesia pada akhir pendudukan Jepun di negara itu. Kedatangannya ke Tanah Melayu juga adalah kerana diburu Belanda akibat kegiatannya dalam Parti Komunis Indonesia. Lihat Ramlah Adam, Burhanuddin al-Hemly, Suatu Kemelut Politik. Kuala Lumpur: Dewan Bahasa Pustaka, 2003 (cetakan ketiga), hlm. 37.

${ }^{27}$ Temu bual Ramlah Adam dengan Yahya Nasim, bekas Presiden PKMM Selangor pada 1/1/91 di Hulu Langat, Selangor. Yahya Nasim merupakan bekas pelajar al-Ehya. Menurutnya, minat politik yang disemai di maahad berkenaan menyebabkan para pelajar memberi sokongan kepada PKMM dan API secara meluas terutamanya setelah mendengar ucapan Dr. Burhanuddin. Lihat Ramlah Adam, Burhanuddin al-Hemly, Suatu Kemelut Politik, hlm. 66.

${ }^{28}$ Utusan Melayu 24 Feb 1948, artikel bertajuk "Perjuangan MATA dalam Federation soal parti Islam diperhatikan.” 
29 Utusan Melayu, 28 Januari dan 18 Februari 1948 memuatkan berita tentang MATA yang tidak berpuas hati dengan Majlis Agama Negeri yang terikat dengan sekatan golongan feudal.

${ }^{30}$ Ibid.

${ }^{31}$ CO 537/3751, Malayan Security Service, Political Intelligence Journal, No. 6/1948, 31 Mac 1948, hlm. 177. Penubuhan Hizbul Muslimin juga berkait rapat dengan pengaruh Dr. Burhanuddin al-Helmy dan PKMM yang menghulurkan pelbagai bantuan dalam penubuhan MATA seterusnya membawa kepada penubuhan Hizbul Muslimin. Lihat Ahmad Bostamam, "Barisan Tani Se-Malaya Diperhebat Perjalanannya," dalam Berita Harian, 15 Ogos 1971, hlm. 12. Keterangan lanjut tentang kegiatan Hizbul Muslimin lihat Abu Hanifah Haris, "Reaksi British Terhadap Kegiatan Hizbul Muslimin di Tanah Melayu, 1948-1949" dalam Prosiding Persidangan Intelektual Kebangsaan Malaysia pada 17-18 April 2013 di Universiti Pendidikan Sultan Idris, Perak.

${ }^{32}$ CO 537/3751, Malayan Security Service, Political Intelligence Journal, No. 8/1948, 30 April 1948, hlm. 258-259.

${ }^{33}$ CO 537/3752, Malayan Security Service, Political Intelligence Journal, No.10/1948, 31 Mei 1948, hlm. 362.

${ }^{34}$ CO537/3751, Malayan Security Service, Political Intelligence Journal, No. 8/1948, 30 April 1948, hlm. 296.

${ }^{35}$ CO 537/3753, Malayan Security Service, Political Intelligence Journal, No.14/1948, 31 Julai 1948, hlm. 544.

${ }^{36}$ CO 537/3751, Malayan Security Service, Political Intelligence Journal, No. 6/1948, 31 Mac 1948, hlm. 175.

${ }^{37}$ CO 537/3751, Malayan Security Service, Political Intelligence Journal, No.9/1948, 15 Mei 1948, hlm. 296

${ }^{38}$ CO 537/3752, Malayan Security Service, Political Intelligence Journal, No.10/1948, 31 Mei 1948, hlm. 362.

${ }^{39}$ Utusan Melayu, 15 Mei 1948, hlm. 3.

${ }^{40}$ CO 537/3751, Malayan Security Service, Political Intelligence Journal, No.9/1948, 15 Mei 1948, hlm. 296

${ }^{41}$ CO 537/3752, Malayan Security Service, Political Intelligence Journal, No.11/1948, 15 Jun 1948, hlm. 416.

${ }^{42}$ CO 537/3752, Malayan Security, Political Intelligence Journal, No.11/1948, 15 Jun 1948, hlm. 415

${ }^{43}$ Utusan Melayu., 18 Mei 1948, hlm. 3.

${ }^{44}$ Utusan Melayu, 2 Jun 1948, hlm. 2.

${ }^{45}$ Mohamed Asri merupakan anak kelahiran Kelantan dan merupakan bekas Pegawai Propaganda API. Setelah API diharamkan, beliau menyertai PETA. Menurut laporan Malayan Security Service (MSS), beliau merupakan Pegawai Khas Hizbul Muslimin. Lihat CO 537/ 3753, Malayan Security Service, Political Intelligence Journal, No. 14/1948, 31 Julai 1948, hlm. 545.

${ }^{46}$ Ibid., hlm. 586.

${ }^{47}$ CO 537/3754, Pan-Malayan Review of Political and Security Intelligence, No.1/1948, 1 September 1948, Part 1, Political Intelligence Review, hlm. 1-2. 
${ }^{48}$ CO 537/3753, Malayan Security Service, Political Intelligence Journal, No.15/1948, 15 Ogos 1948, hlm. 584. Ketiga-tiga mereka ditahan lebih kurang lima tahun dan ditempatkan di beberapa pusat tahanan iaitu bermula di pusat tahanan Taiping (6 bulan), Pulau Jerejak, Pulau Pinang (6 bulan), Tanjung Beruas, Melaka dan Ipoh. Penahanan mereka kemungkinan ada kaitan dengan laporan polis yang dibuat oleh Penghulu Muda yang baru bertugas di Gunung Semanggol pada awal tahun 1948. Beliau merupakan saudara kepada Dato' Zainal Abidin Abas yang merupakan rakan kepada Dato’ Onn Jaafar, pengasas UMNO. Kemungkinan bedar beliau dihantar bertugas di Gunung Semanggol atas kehendak UMNO bagi memantau pergerakan Hizbul Muslimin. Lihat Nabir Haji Abdullah, Maahad Il Ihya Assyariff Gunung Semanggol, hlm. 200.

${ }^{49}$ Lihat Utusan Melayu 2 Ogos 1948 tentang penangkapan mereka.

${ }^{50}$ Temu bual dengan Puan Aniqah Rusda pada 2 April 2018 pukul 9.00 pagi di rumahnya di Taman Panglima, Ipoh, Perak. Menurut keterangan beliau, bapanya terpaksa bergolok gadai menjual segala harta bendanya termasuk menjual ayam peliharaan bagi membangunkan semula Maahad al-Ehya Assyariff.

${ }^{51}$ Lihat Utusan Melayu, 6 Ogos 1948, hlm. 4 dan Majlis 6 Ogos 1948, hlm. 5. Lihat juga Nabir bin Haji Abdullah, Maahad II Ihya Assyariff Gunung Semanggol 1934-1959, 1976, hlm. 203 berkaitan jumlah pelajar yang semakin berkurangan sejak penangkapan berlaku hinggalah kepada pembukaan kembali maahad tersebut pada 13 Ogos 1948. Dalam tempoh tersebut, Maahad al-Ehya Assyariff telah kehilangan separuh pelajarnya, iaitu daripada seramai 492 orang menjadi 250 orang sahaja. Pada Disember 1949 pula, berlaku penangkapan kali kedua secara beramai-ramai kepada guru-guru Maahad al-Ehya Assyariff dan aktivis API di Gunung Semanggol sehingga menyebabkan kira-kira 100 orang lagi pelajar meninggalkan maahad tersebut kerana faktor keselamatan. Malah pada 1951, hanya tinggal 70 orang pelajar sahaja yang masih menuntut. Ketika itu penuntut maahad ini hanyalah anak-anak tempatan yang berada sekitar kampung di Gunung Semanggol sahaja.

${ }^{52}$ Lihat Abu Zaki, "Belalah Nasib Penuntut-penuntut Sekolah Ugama," Penuntut, (Majalah Triwulan Gabungan Pelajar-Pelajar Melayu Semenanjung-GPMS), Bil.1, tahun1, Kuala Lumpur, 1950, hlm. 8.

${ }^{53}$ Sultan Perak dan Menteri Besar ketika itu, Datuk Hj Abdul Wahab bin Toh Muda Abdul Aziz turut membuat lawatan pada 1953 dalam usaha merintis hubungan dengan Maahad al-Ehya Asshariff yang sebelum ini begitu lantang mengkritik kerajaan negeri, pejabat agama dan istana. Malah, semasa Ustaz Abu Bakar al-Baqir dalam tahanan di Taiping, beberapa kali pihak Majlis Agama dan Adat Negeri Perak melawatinya dan menawarkan kepada beliau jawatan dalam institusi tersebut. Namun, beliau menolak dengan alasan ingin menumpukan segala perhatiannya menghidupkan semula maahadnya dan atas dasar kepercayaan itulah, beliau dibebaskan. Lihat Nabir Haji Abdullah, Maahad II Ihya Assyariff Gunung Semanggol 1934-1959, 1976, hlm. 209 dan 211.

${ }^{54}$ Laporan Masyuarat Agung Tahunan, Persatuan II Ihya Berhad dalam Fail Setiausaha 21 April 1954.

${ }^{55}$ Lihat Nabir bin Haji Abdullah, Maahad II Ihya Assyariff Gunung Semanggol 1934-1959, 1976, hlm. 230.

${ }^{56}$ Report of the First Election of the Legislative Council the Federation of Malaya, Government Press, Kuala Lumpur, 1955, hlm 69. 


\section{RUJUKAN}

Abu Bakar al-Baqir. (1973). Gerakan-gerakan politik yang berunsur atau berkaitan dengan ugama Islam di Malaysia. Kertas Kerja Seminar ME 405-Siri Tokoh-tokoh Malaysia pada 19 September 1973. Jabatan Sejarah, Universiti Kebangsaan Malaysia.

Abu Hanifah Haris. (2013). Reaksi British terhadap kegiatan Hizbul Muslimin di Tanah Melayu 1948-1949. Prosiding Persidangan Intelektual Kebangsaan Malaysia pada 17-18 April 2013. Universiti Pendidikan Sultan Idris, Perak. Abu Zaki. (1950). Belalah nasib penuntut-penuntut sekolah ugama. Penuntut, (Majalah Triwulan Gabungan Pelajar-Pelajar Melayu Semenanjung-GPMS), Bil.1, tahun1, Kuala Lumpur.

Al Ihya Assyarif. (1959). Buku Peringatan Suku Abad (sempena sambutan Jubilee Perak), November 1959.

Al-Ihya. (1947). Pulau Pinang: Lembaga Pustaka al-Ihya, Persama Press, 1947, Bil 1, tahun 1.

Berita Harian, 15 Ogos 1971.

CO 537/3751, Malayan Security Service, Political Intelligence Journal, No. 6/1948, 31 Mac 1948.

CO 537/3751, Malayan Security Service, Political Intelligence Journal, No. 8/1948, 30 April 1948.

CO 537/3751, Malayan Security Service, Political Intelligence Journal, No.9/1948, 15 Mei 1948.

CO 537/3752, Malayan Security Service, Political Intelligence Journal, No.10/1948, 31 Mei 1948.

CO 537/3752, Malayan Security Service, Political Intelligence Journal, No.11/1948, 15 Jun 1948.

CO 537/3753, Malayan Security Service, Political Intelligence Journal, No.14/1948, 31 Julai 1948.

CO 537/3753, Malayan Security Service, Political Intelligence Journal, No.15/1948, 15 Ogos 1948,

CO 537/3754, Pan-Malayan Review of Political and Security Intelligence, No.1/1948, 1 September 1948, Part 1, Political Intelligence Review.

Ibrahim Haji Yaakub. (1973). Sejarah Perintis Kemerdekaan Malaysia (bahagian kedua). Kertas kerja Seminar ME 405, Sejarah Tokoh-Tokoh Malaysia pada 29 Ogos 1973. Jabatan Sejarah, Universiti Kebangsaan Malaysia.

Ishak Hj Muhammad. (1973). Politik Tanah Melayu hingga pendudukan Jepun. -Siri

Sejarah Tokoh-Tokoh Malaysia pada 24 Julai 1973, Jabatan Sejarah, UKM.

Khairul Nizam Zainal Badri. (2008). Ketokohan dan Pemikiran Abu Bakar al-Baqir, Karisma Publication, Shah Alam.

Means, G. P. (1970). Malayan Political. London: University of London Press Ltd. 
Nabir Abdullah. (1976). Maahad Il Ihya Assyariff Gunung Semanggol 1934-1959, Kuala Lumpur: Universiti Kebangsaan Malayasia.

Ramlah Adam. (2003). Burhanuddin al-Hemly, suatu kemelut politik. Kuala Lumpur: Dewan Bahasa dan Pustaka.

Report of the First Election of the Legislative Council the Federation of Malaya. (1955). Kuala Lumpur: Government Press.

Saari Sungib. (2010). Tokoh-tokoh besar Gerakan Islam dalam sejarah. Selangor: Rijal Media.

Silcock \& Aziz. (1950). Nationalism in Malaya, 11 th Conference Institute of Pacific Relations, Lucknow India, October 3-15, 1950.

Harper, T. N. (2001). The end of empire and the making of Malaya. Cambridge: Cambridge University Press.

Utusan Malaysia, 6 November 2016.

Utusan Melayu, 28 Jan, 18 Feb, 24 Feb, 2 Jun, 15 Mei, 18 Mei 1948.

Temu bual bersama Puan Aniqah Rusda binti Abu Bakar pada 2 November 2013 dan 2 April 2018 bertempat di Taman Panglima, Ipoh, Perak.

Temu bual bersama Dr. Sabri Salamon pada 27 Disember 2016 di Felda Kampung Awah, Temerloh, Pahang. 
